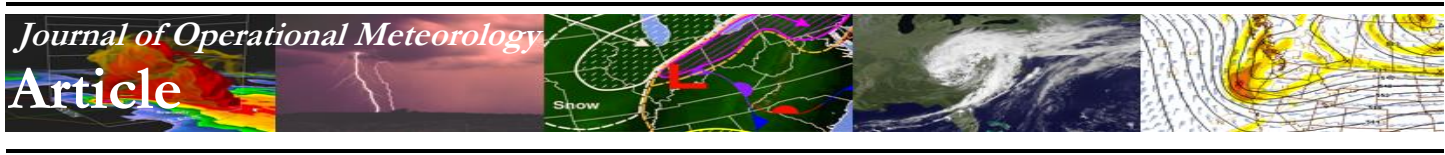

\title{
A Forecast Procedure for Dry Thunderstorms
}

\author{
NICHOLAS J. NAUSLAR and MICHAEL L. KAPLAN \\ Desert Research Institute, Reno, Nevada \\ JAMES WALLMANN \\ National Weather Service, Reno, Nevada \\ TIMOTHY J. BROWN \\ Desert Research Institute, Reno, Nevada
}

(Manuscript received 7 September 2012; review completed 14 March 2013)

\begin{abstract}
Dry thunderstorms (traditionally $<2.5 \mathrm{~mm}$ or 0.1 in of rainfall) have long challenged the weather forecasting community in the western United States (Pacific coast to the Rocky Mountains). Dry thunderstorms are responsible for starting thousands of wildland fires every year, including hundreds of fires in $\mathbf{2 4} \mathrm{h}$ during larger events. The National Weather Service (NWS) Weather Forecast Office (WFO) in Reno, Nevada, developed a conceptual model for dry lightning called the dry lightning procedure (DLP); this includes the pressure of the dynamic tropopause (DT) on the 1.5 isentropic potential vorticity (IPVU) surface, various vertical motion structures based on straight and curved jet configurations, 850-700-hPa layer-average equivalent potential temperature $\left(\theta_{e}\right)$, high-level total totals (HLTT), and upper-tropospheric lapse rates (UTLR). The research described herein substitutes cross sections of $\theta_{e}$, mixing ratio, and relative humidity for the 850-700-hPa layer-average $\theta_{e}$ in a modified version of the DLP. It also adds 250-hPa divergence plots to better ascertain vertical motions associated with straight and curved jets. These two additions, along with the rest of the DLP (DT on 1.5 IPVU surface, HLTT, UTLR) form the dry thunderstorm procedure (DTP).

This paper examines the DTP for three case studies, including an overforecast event. The DTP adequately exhibited the ability to depict the potential for dry thunderstorms based on these case studies. The Reno WFO, and two interagency Geographical Area Coordination Center's Predictive Services offices, have implemented the DTP operationally to ascertain the potential for dry thunderstorms.
\end{abstract}

\section{Introduction}

Dry thunderstorm events [i.e., receiving either $<2.5 \mathrm{~mm}(0.1 \mathrm{in})$ of rainfall or cloud-to-ground $(\mathrm{CG})$ strikes outside the main rain core] create numerous fire starts in the western United States, which stress local and regional fire suppression resources. Most of the significant dry thunderstorm events that produce thousands of CG strikes and hundreds of fires occur in the western United States (Pacific coast to the Rocky Mountains) between May and September. From 2001 to 2008 lightning ignited a yearly average of 11912 fires, totaling nearly 4.5 million acres burned. This accounts for approximately $65 \%$ of total acres burned per year (explore.data.gov/Natural-Resources/LightningCaused-Fires-and-Acres/89ei-yhw5). The cost of fighting wildfires exceeds $\$ 1$ billion annually-just from the
United States Forest Service-in addition to the millions of dollars in property loss (www.fs.fed.us/ aboutus/budget). The monetary cost can pale in comparison to the fatalities and injuries incurred by firefighters and the public each year.

Fire management heavily utilizes weather forecasts for tactical planning and resource allocation. Thus, it is reasonable to assume that better forecasting of dry thunderstorm events could lead to more efficient and productive fire management, as well as fire fighter and public safety. For example, if fire managers and government officials had 24-48 h of lead time, more efficient steps could be taken to prepare resources for multiple fire starts, and thus reduce the chance of costly, large fires. 
Many of these dry thunderstorm events occur with an upper-level trough approaching the western United States juxtaposed with monsoonal moisture advected from the south. Monsoonal moisture can be defined as an influx of moisture advected northward, westward, and/or eastward-originating from the Gulfs of California and/or Mexico during the North American warm season (Douglas et al. 1993). From a forecasting perspective, it can be difficult to predict the location of high-based convection, or to delineate dry and wet thunderstorms, owing to the spatially and temporally variable advection of moisture and areas of instability. Lower-tropospheric thunderstorm indices, such as total totals (TT), convective available potential energy (CAPE), K-index, and lifted index (David 1976; Stull 2000; Doswell 2001), struggle to indicate thunderstorm potential because of the complex terrain and the high bases of thunderstorms that predominate in many areas of the western United States.

Many studies have described procedures aimed to predict dry thunderstorms by determining the importance of midlevel (850-500-hPa) instability, low-level $(850 \mathrm{hPa})$ dewpoint depressions, and certain warmseason synoptic patterns (Rorig and Ferguson 1999, 2002; Rorig et al. 2007). Bothwell (2002, 2005, 2009) developed statistical techniques to predict thunderstorms by performing logistic regression on more than 200 candidate predictors from model forecast and analysis data to develop the perfect prognosis forecast equations for $\geq 1, \geq 10$, and $\geq 100 \mathrm{CG}$ flash probabilities across the United States. Bothwell built upon this research and developed the dry thunderstorm potential index, which provides a numerical value for dry thunderstorm potential.

Wallmann (2004) and Wallmann et al. (2010) described a dry lightning forecast procedure (DLP), which includes the use of the dynamic tropopause (DT) on the 1.5 isentropic potential vorticity unit (IPVU) surface, jet-streak locations to delineate areas of stronger forcing for ascent due to ageostrophic motions, $850-700-\mathrm{hPa}$ layer-average equivalent potential temperature $\left(\theta_{e}\right)$, upper-tropospheric (500300-hPa) lapse rates (UTLR), and high-level TT (HLTT; Milne 2004). Wallmann (2004) described the dry lightning event that occurred over the Great Basin on 12 August 2001, and Wallmann et al. (2010) detailed how the DLP forecasted the 21 June 2008 northern California dry lightning event in advance.

The DLP provided the foundation for the dry thunderstorm procedure (DTP), described in this paper. The DTP adds two components, while remov- ing one. It excludes the 850-700-hPa layer-average $\theta_{e}$, and incorporates 1) vertical cross sections of $\theta_{e}$ and mixing ratio, and vertical cross sections of $\theta_{e}$ and relative humidity $(\mathrm{RH})$, and 2) divergence of the 250 $\mathrm{hPa}$ horizontal winds. The cross sections represent the main procedure enhancement while the $250-\mathrm{hPa}$ divergence and wind plots allow for examination of instability and forcing by implementing techniques from Uccellini and Johnson (1979) and Moore and VanKnowe (1992), with support from Kaplan et al. (1998) and Hamilton et al. (1998).

The purpose of this paper is to demonstrate how the DTP improves upon the DLP by locating and illustrating the potential instability (PI) and moisture in the troposphere more clearly and efficiently. In order to show this, we apply the DTP to three case studies instead of just one as was done by Wallmann (2004) for the DLP. Four additional case studies can be found in Nauslar (2010). Section 2 describes the DTP, including its improvements upon the DLP and the data employed in the analyses of the case studies. Section 3 discusses the application of the DTP for the case studies and the results of the analyses. Section 4 summarizes the findings.

\section{Methods and data}

\section{a. Methods: Dry thunderstorm procedure (DTP)}

The DTP includes three parameters (briefly described here) directly from the DLP including: UTLR, HLTT, and the DT on the 1.5 IPVU surface analyses fields (Wallmann et al. 2010). UTLR comprises the 500-300-hPa layer, which can be employed to ascertain instability aloft without the influence of the planetary boundary layer (PBL) while accounting for the higher cloud bases prevalent throughout the western United States, especially in the Intermountain West. Wallmann (2004) and Wallmann et al. (2010) demonstrated that UTLR values of $\geq 7.5^{\circ} \mathrm{C} \mathrm{km}^{-1}$ could sustain dry thunderstorm development with adequate low- or mid-level moisture.

Milne (2004) developed the HLTT from the traditional TT. Both indices measure the potential for thunderstorm development and coverage. The HLTT is calculated by summing these three variables: $700-\mathrm{hPa}$ temperature, $700-\mathrm{hPa}$ dewpoint, and twice the $500-\mathrm{hPa}$ temperature. Milne (2004) and Wallmann et al. (2010) demonstrated that an HLTT value of $28^{\circ} \mathrm{C}$ is an appropriate threshold for thunderstorms in the mountainous terrain of the western United States. 
The DT on the 1.5 IPVU surface maps depicts the pressure of the tropopause, which illustrates shortwave troughs and disturbances embedded in the flow that otherwise may go unnoticed at mid-tropospheric analysis levels (Hirschberg and Fritsch 1991a,b; Wallmann et al. 2010). A more detailed explanation of these parameters can be found in Wallmann (2004) and Wallmann et al. (2010).

Diagnosing the vertical profile of instability and moisture represent the two biggest difficulties in forecasting dry thunderstorms. Vertical cross sections became a logical addition to the DLP and an integral part of the DTP for several reasons. On the large mesoscale (i.e., 200-2000 km, Orlanski 1975), isentropic surfaces offer improved three-dimensional thermodynamic information where baroclinic zones slope substantially. Motion along strongly sloping isentropic surfaces includes fine-scale moist tongues that are poorly resolved on quasi-horizontal pressure surfaces (UCAR 2002). Isentropic surfaces tend to be steeper across the same thermal gradient than constantheight or pressure surfaces; therefore, they can be used to discern and diagnose instability and moisture, which helps in locating potential dry thunderstorm areas.

The authors initially plotted potential temperature ( $\theta$ ) with the use of mixing ratio and $\mathrm{RH}$ on vertical cross sections using the General Meteorology Package (www.unidata.ucar.edu/software/gempak). However, $\theta_{e}$ is appropriate for defining PI $\left(\mathrm{d} \theta_{e} / \mathrm{dz}<0\right)$ in the atmosphere, and thus $\theta_{e}$ was substituted for $\theta$. The decision on the path of the cross section is important for a forecaster when trying to diagnose fine-scale phenomena. Multiple cross sections can be drawn over a region, which is why local knowledge from forecasters plays an important role in focusing on specific locations for cross sections. For example, the area of forecast responsibility for a National Weather Service (NWS) Weather Forecast Office (WFO) is small enough to have a restricted number of cross sections to adequately resolve the potential for dry thunderstorms.

An important finding is that these plots show that PI and moisture often are collocated to form an environment conducive for thunderstorms, especially dry thunderstorms. Because $\theta_{e}$ is a function of moisture and temperature, it is not entirely surprising to find collocated areas of PI with higher quantities of mixing ratio and RH. PI can exist without higher values of mixing ratio and $\mathrm{RH}$, while the converse of this situation also is true. However, an increase of moisture will provide a profile of $\mathrm{d} \theta_{e} / \mathrm{dz}<0$ even without mid- to lower-tropospheric instability-the latter of which can result from lifting mechanisms or differential vertical advections. This is very important above the mid-troposphere in the Intermountain West. The prototypical dry thunderstorm tropospheric structure relies on mid-tropospheric PI (with or without an increase of moisture) and moisture with a drier lower troposphere. No mixing ratio or $\mathrm{RH}$ thresholds were set to determine whether adequate or excessive moisture existed for dry thunderstorms.

Divergence and winds at $250 \mathrm{hPa}$ were plotted to ascertain the upper-tropospheric jet structure. Transverse circulations are established in the entrance and exit regions of the straight jet streak, while alongstream circulations produce a convergent entrance region and divergent exit region in the curved jet. These regions produce ascent-induced cooling that results in dynamical destabilization of a layer (Uccellini and Johnson 1979; Moore and VanKnowe 1992). These divergent regions can evolve subsynoptic structures, especially when the flow becomes unbalanced as it departs from the traditional jet streak and quasi-geostrophic theory-owing to outflow from upstream convection (Hamilton et al. 1998; Kaplan et al. 1998). The sub-synoptic structures, manifested in the form of mesoscale jets (jetlets) due to an ageostrophic response to the perturbation in the mass field from latent heating, produce highly diffluent areas that can support subsequent downstream ascent that triggers new convection (Hamilton et al. 1998; Kaplan et al. 1998).

The times examined for each event were 24-48 h before the event occurred. Each part of the DTP was examined to ascertain the prediction potential of the DTP. Not all components of the DTP indicated dry thunderstorm potential during the same Global Forecast System (GFS) and North American Mesoscale (NAM) model forecast. However, each component did indicate dry thunderstorm potential to occur at the same time by the 36-h NAM or GFS forecast for each event. Thus, a forecaster may need to synthesize information across multiple model runs to gain confidence in a forecast for dry thunderstorms.

\section{b. Data}

The results described in this paper are based on the GFS and NAM model simulations (www.emc.ncep. noaa.gov/index.php?branch=NAM). The DTP is meant to use data readily available to operational forecasters to assess dry thunderstorm potential $24-48 \mathrm{~h}$ in 
advance. GFS and NAM model runs were obtained from the NOAA Operational Model Archive and Distribution System (NOMADS; nomads.ncdc.noaa.gov). The GFS data obtained employ a $1^{\circ}$ grid and provide forecasts every 3,6 , or $12 \mathrm{~h}$ out to $384 \mathrm{~h}$. The NAM data obtained employ a $12-\mathrm{km}$ grid and provide forecasts every $3 \mathrm{~h}$ out to $84 \mathrm{~h}$. The GFS and NAM each produced runs initialized at 0000, 0600, 1200, and 1800 UTC, which were viewed up to $48 \mathrm{~h}$ preceding each event. GEMPAK and the Advanced Weather Interactive Processing System (NWS 2007) were used to plot the data after converting the NOMADS gridded binary files to a suitable format.

The Program for Climate, Ecosystem, and Fire Applications (CEFA) at the Desert Research Institute (DRI) provided lightning strike data from the National Lightning Detection Network ${ }^{\mathrm{TM}}$. Twelve-hour lightning data were plotted from 0000 to 1200 UTC and 1200 to 0000 UTC for each day during the event using the National Center for Atmospheric Research Command Language software (www.ncl.ucar.edu). The National Incident Coordination Center daily situation reports provided the fire ignition data (NICC 2006, 2007, 2009). Precipitation data from the Hourly Precipitation Database (www7.ncdc.noaa.gov/IPS/hpd/ hpd.html), Remote Automated Weather Stations, and North American Regional Reanalysis (Mesinger et al. 2006) were analyzed to determine rainfall totals.

\section{Analysis and results}

Three cases were selected to demonstrate the DTP. Two cases exhibit the application of the DTP to dry thunderstorm events that ignited hundreds of fires, while the third case represents an overforecast. The 20-21 June 2008 dry thunderstorm event, which helped provide the impetus for creating the DTP, was one of the events not forecasted well and will be compared directly to Wallmann et al. (2010).

\section{a. Comparison of DTP and DLP: 20-21 June 2008}

During 20-21 June 2008 in northern California, predominantly dry thunderstorms produced over 5000 lightning strikes, which ranked in the top five of lightning strikes ever observed during a 24-h time period for northern California. Convection occurred offshore in the previous $24 \mathrm{~h}$, providing evidence of the approaching moisture and instability. This moisture and instability progressed onshore during the afternoon and evening of 20 June 2008 helping initiate convection across northern California. The lightning ignited 602 fires throughout northern California by 0000 UTC 22 June (dashed oval in Fig. 1b), which overwhelmed the local and regional fire management (Fig. 1). Twelve firefighters lost their lives and the monetary cost of fighting the fires reached nearly $\$ 300$ million (Wallmann et al. 2010). Wallmann et al. (2010) applied the DLP to this event, which provides an opportunity to compare the DLP and DTP, and demonstrate improvements to dry thunderstorm forecasting.


Figure 1. a) Map of large fires in the United States the morning of 23 June 2008, courtesy of NICC in Boise, ID (Wallmann et al. 2010); b) Lightning strike plot from 1200 UTC 21 June to 0000 UTC 22 June 2008. The dashed line shows the location of the OAK-MFR cross section in Fig. 2. and the dashed oval surrounds the area of study. Click image for an external version; this applies to all figures hereafter.

The NAM and GFS 48-h model forecast vertical cross sections from Oakland, California (OAK), to 
Medford, Oregon (MFR), indicated instability and moisture surrounding $700 \mathrm{hPa}$ with drier and more stable conditions below across northern California (Fig. 2). The NAM forecasts (Figs. 2a and 2b) were valid at 0000 UTC 21 June and the GFS forecasts (Figs. 2c and 2d) were valid at 0600 UTC 21 June. A midlevel plume of moisture formed between 750 and $600 \mathrm{hPa}$. This plume developed because of the confluence of tropical and subtropical streams of moisture originating near Hawaii and from moisture generated from thunderstorms circulating around a ridge near Baja California and the Sierra Madre Occidental. A noticeable increase of $\mathrm{RH}$ and mixing ratio existed in the $750-600-\mathrm{hPa}$ layer, which was collocated with areas of an increased temperature lapse rate (i.e., reduced dry static stability) in the 750-500$\mathrm{hPa}$ layer displayed by the cross sections across northern California (Fig. 2). The cross sections illustrate the increase of moisture and PI overlying a drier lower troposphere, providing an example of an environment conducive for high-based convection.

Wallmann et al. (2010) used supporting plotsincluding $\mathrm{RH}$ at different levels, mass advection on different $\theta$ surfaces ( 310 and $315 \mathrm{~K}$ ), temperature advection at different pressure levels, 700-hPa frontogenesis, and most-unstable layer CAPE-to support the DLP, and confirm the presence of sufficient PI and moisture to depict a region favorable for dry thunderstorm development. Implementing the vertical cross sections from the DTP makes these supporting plots unnecessary since the PI and moisture can be seen in one encompassing cross section of the troposphere. a)

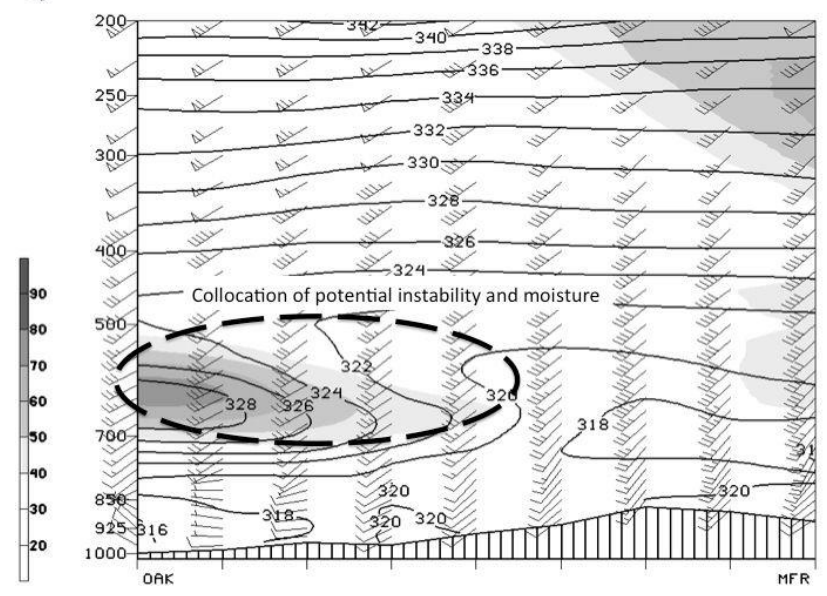

c)

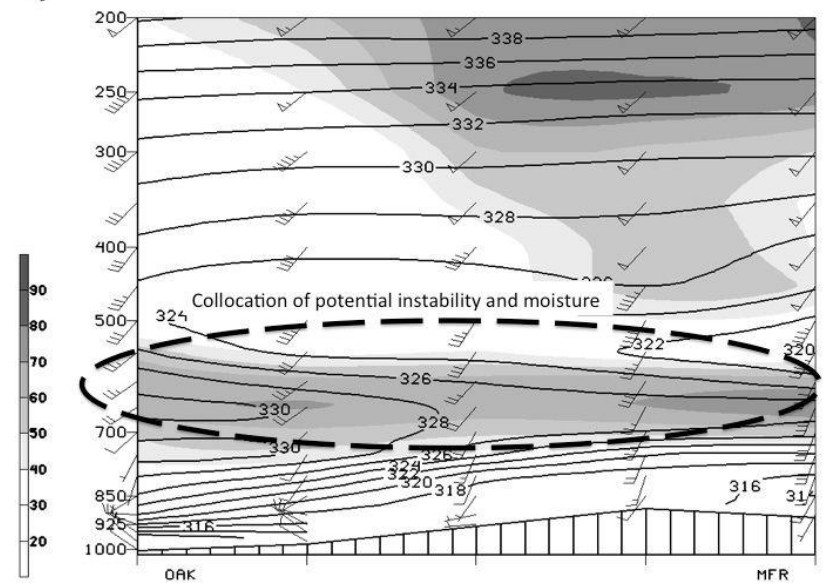

b)

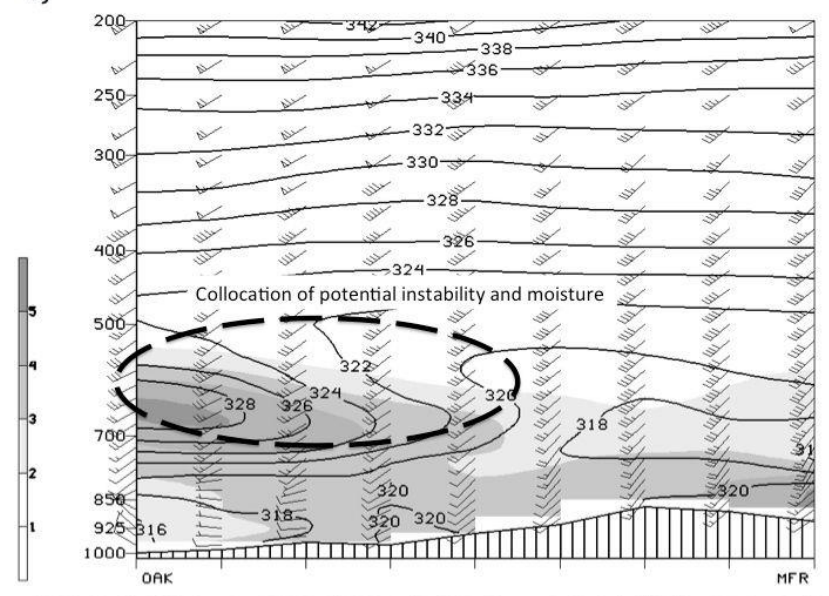

d)

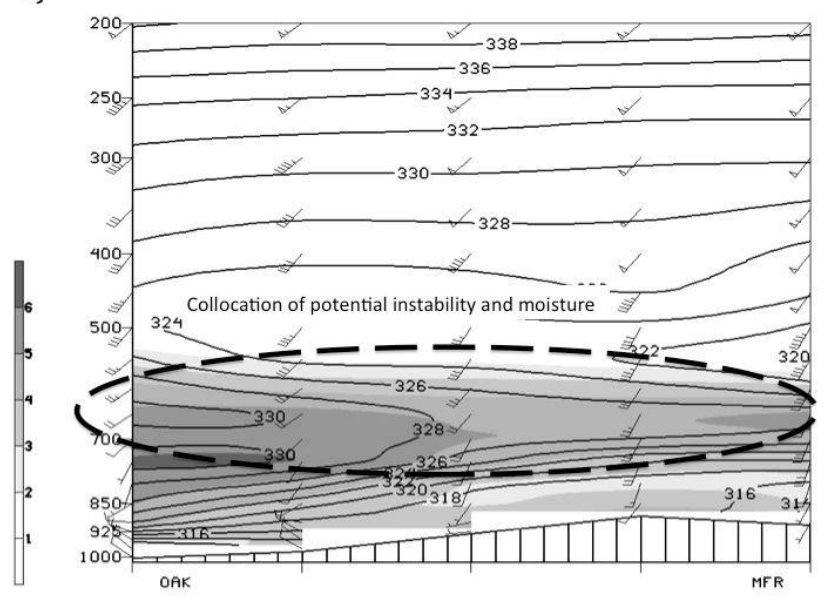

Figure 2. a) 0000 UTC 19 June 2008 48-h NAM forecast vertical cross section of RH (filled every $10 \%$ starting at 50\%) and $\theta_{e}$ (contoured every $2 \mathrm{~K}$ ) from OAK to MFR; b) 0000 UTC 19 June 2008 48-h NAM forecast vertical cross section of mixing ratio (filled every $1 \mathrm{~g} \mathrm{~kg}^{-1}$ ) and $\theta_{e}$ (contoured every $2 \mathrm{~K}$ ) from OAK to MFR; c) Same as a) except for 0600 UTC 19 June 2008 48-h GFS forecast; d) Same as b) except for 0600 UTC 19 June 2008 48-h GFS forecast. The dashed oval in each cross section shows the collocation of PI and moisture. 
With the offshore convection and the upward vertical motion forecast to occur in the eastern Pacific west of the coast of California, the associated latent heat release resulted in mesoscale pressure perturbations. These mesoscale pressure perturbations can produce fine-scale jet structures that may further organize upward vertical motions (Hamilton et al. 1998). Such a mesoscale divergent region arrived above the coast just west of San Francisco Bay in the 48-h GFS forecasts (Fig. 3). This can be distinguished from the larger area of divergence to the west and northwest that was associated with the main core of the quasi-geostrophic system lying just west-southwest of the northern California coast. This area of divergence gave rise to parcel vertical motions resulting from convectively induced horizontal accelerations - consistent with the diabatic isallobaric component of the ageostrophic wind on isentropic surfaces (Kaplan et al. 1998). The ensuing jetlet can be seen as a ageostrophic wind appendage of the larger polar jet on its right forward flank exceeding $30 \mathrm{~m} \mathrm{~s}^{-1}$ $(60 \mathrm{kt})$ and approaching the coast on the $250-\mathrm{hPa}$ surface during 0000-0600 UTC 21 June (Fig. 3). The lifespan of this jetlet was consistent with other jetlets of 3-12 h (e.g., Hamilton et al. 1998). The 250-hPa wind and divergence plots illustrate not only the jetlet, but also the coupled mesoscale divergence away from the core of the polar jet. The DTP 250-hPa wind and divergence plot provides a more complete tool than the DLP 250-hPa wind plot when analyzing instability and upward motion associated with jet streaks.

The DTP and the DLP both contain the remaining forecasting components of tropopause pressure on the 1.5 IPVU surface, HLTT, and UTLR. Therefore, a brief review of the remaining plots will suffice. In Fig. $4 \mathrm{a}$, the GFS forecast shows a weak undulation in the tropopause across northern California in the same region as the flow of moisture and dry thunderstorm formation. This feature helped destabilize the mid- to upper troposphere and possibly resulted from, in part, the offshore convection and subsequent highly divergent jetlet. The HLTT easily reached the minimum forecast thresholds owing to the most significant moisture and instability residing in the 700-500-hPa layer, and offers more evidence of the likelihood of offshore convection as the threshold was met well off the coast. The HLTT values from both the NAM and GFS forecasts met the threshold, although the GFS more accurately portrayed the highly unstable atmosphere over the region (Figs. $4 \mathrm{~b}$ and $4 \mathrm{c}$ ). The GFS forecast in Fig. 4d shows a UTLR value exceeding
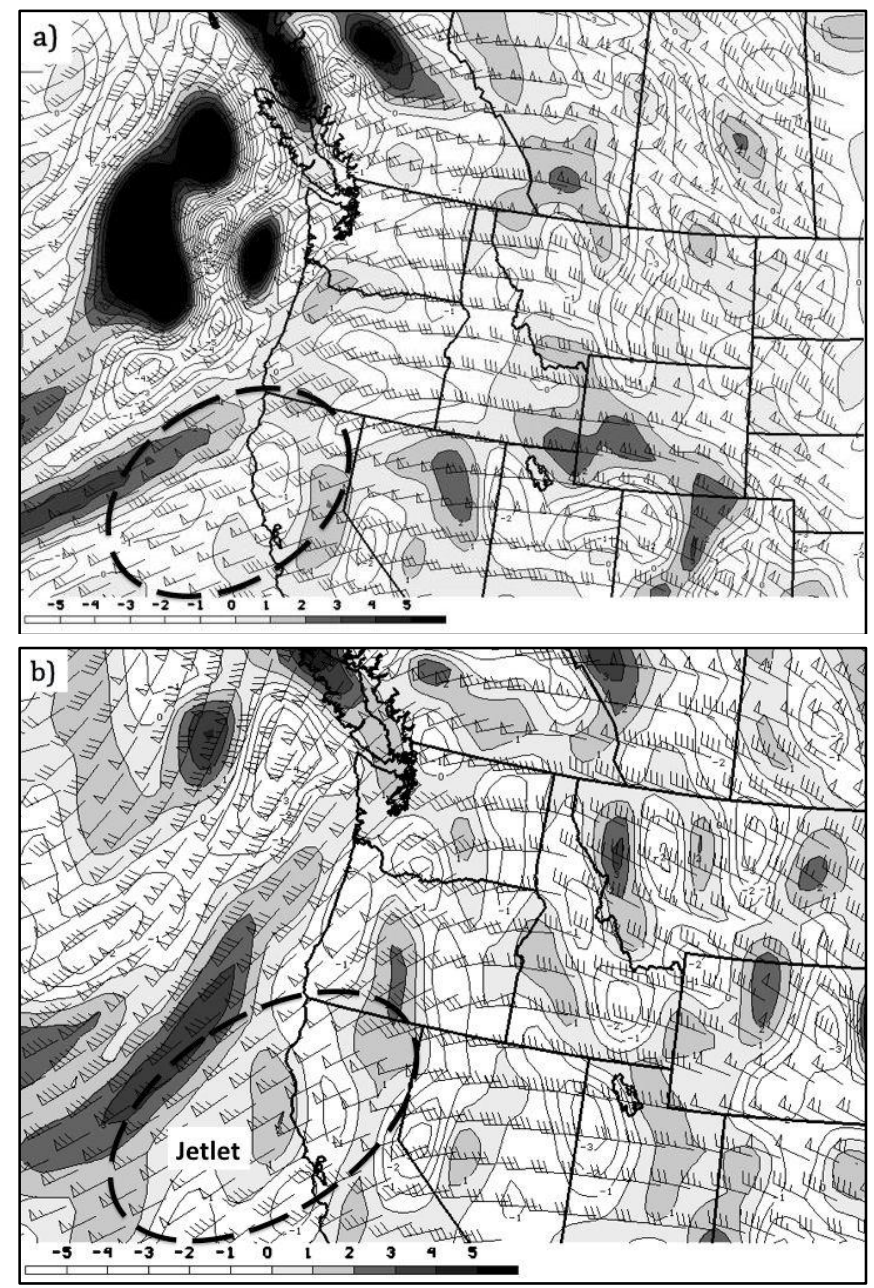

Figure 3. a) 0000 UTC 19 June 2008 48-h GFS forecast $250-\mathrm{hPa}$ winds (kt) and divergence (shaded, contoured every $1 \times 10^{-5} \mathrm{~s}^{-1}$ ); b) Same as a) except for 0600 UTC 19 June 2008 48-h GFS forecast. The dashed oval shows the location of the forecast jetlet.

$8^{\circ} \mathrm{C} \mathrm{km}^{-1}$, with all of northern California reaching the $7.5^{\circ} \mathrm{C} \mathrm{km}^{-1}$ threshold.

The DTP resolved the ingredients and predicted the event more clearly than the DLP-especially without the supporting plots featured in Wallmann et al. (2010). Moisture flowed above the surface between constant-pressure layers because of the long-term forcing of upward vertical motion and quasi-horizontal transport. The DTP cross sections and 250-hPa wind and divergence plots illuminated the potential for dry thunderstorms more efficiently and completely than its predecessor DLP by eliminating extraneous supporting plots and highlighting the vertical distribution of moisture and instability more accurately. The cross sections reveal the amount of moisture and instability between 750 and $500 \mathrm{hPa}$. Accelerating flow due to latent heat release from convection over the eastern 

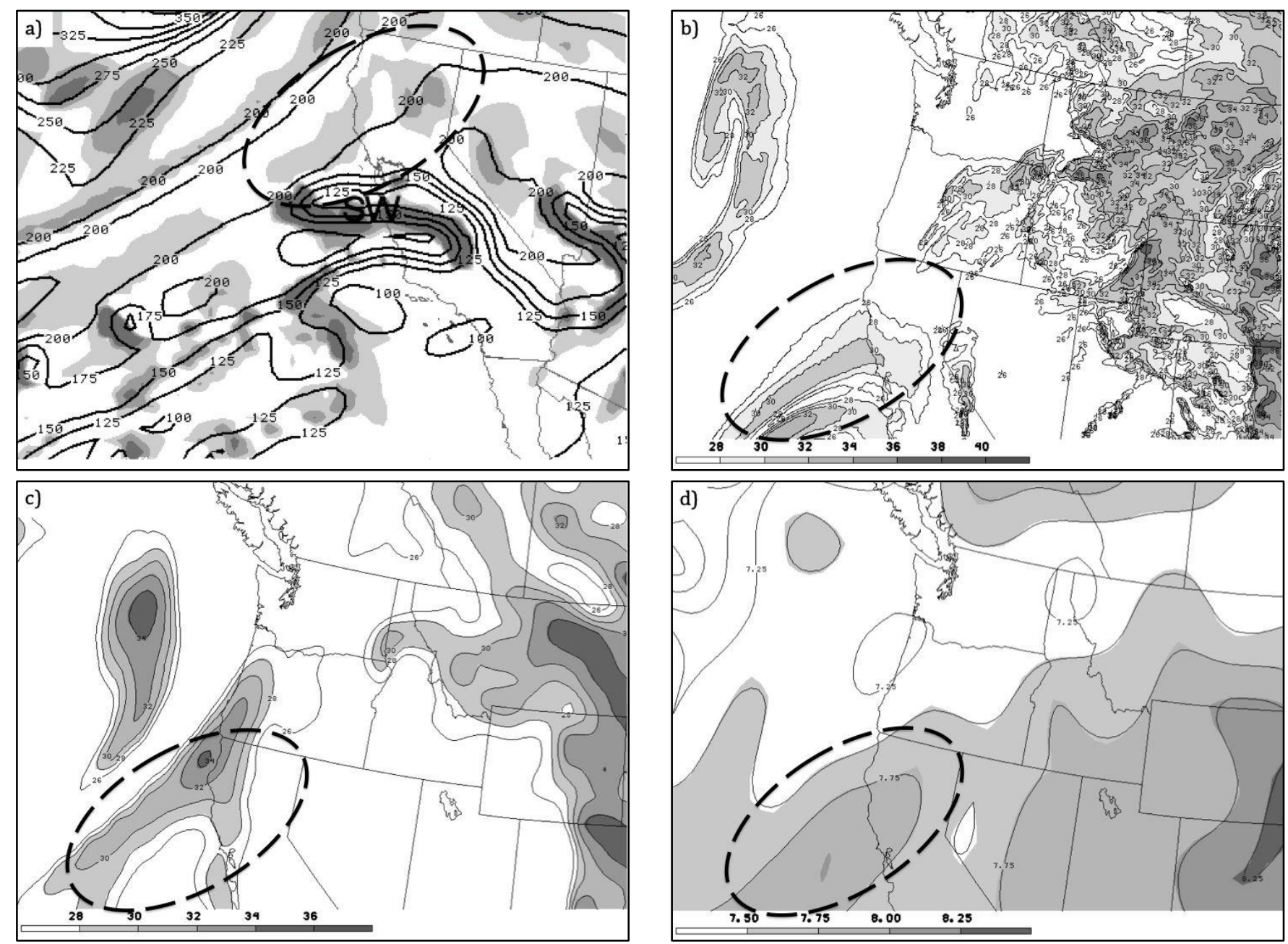

Figure 4. a) 0000 UTC 19 June 2008 48-h GFS forecast of DT pressure (contoured, hPa) plotted on the 1.5 IPVU surface and pressure advection omega $\left(\mu \mathrm{b} \mathrm{s}^{-1}\right.$, shaded: light $>0$, medium $>2$, and dark $>5$ ). SW denotes short-wave trough location (Wallmann et al. 2010); b) 0000 UTC 19 June 2008 48-h NAM forecast of HLTT (contoured and filled every $2^{\circ} \mathrm{C}$ ); c) 0600 UTC 19 June 2008 48-h GFS forecast of HLTT (contoured and filled every $2^{\circ} \mathrm{C}$ ); d) 0600 UTC 19 June 2008 48-h GFS forecast of UTLR (contoured and filled every $0.25^{\circ} \mathrm{C} \mathrm{km}{ }^{-1}$ ).

Pacific Ocean helped perturb the mass and wind fields to form a jetlet, which supported and enhanced the convection as it came onshore as shown by the 250 $\mathrm{hPa}$ wind and divergence plots. The strength of the DTP compared to the DLP lies with the fact that it employs information at multiple levels, and aims to identify certain moisture and instability signals that the forecasting of this event required.

\section{b. Comparison of DTP and DLP: 16-17 July 2007}

Dry thunderstorms formed quickly early on 16 July 2007 in eastern Nevada, then spread in coverage across all of northern Nevada and southern Idaho over the next $36 \mathrm{~h}$ (dashed oval in Fig. 5). Lightning strikes ignited over 150 fires, including more than 20 large fires with areas $>1.2 \mathrm{~km}^{2}$ (>296 ac) (Fig. 5a; NICC
2007). A weak short-wave trough rotating around the ridge and the extreme southern branch of a $250-\mathrm{hPa}$ curved jet combined with monsoonal moisture to trigger convection over the area in the 1200 UTC 14 July 48-h NAM forecast between 1200 and 1800 UTC 16 July 2007 (Fig. 5b.) The 250-hPa divergence and wind plots and the cross sections resolved the structure of the jet and fringe of the monsoonal moisture in the mid- to upper-levels to show the collocation of the PI and moisture with more stable and drier conditions below. The DTP demonstrates its advantages by illustrating clearly the moisture and PI that produced dry thunderstorms over the central Great Basin.

Figure 6 depicts pockets of PI aloft in the 48-h NAM and GFS forecasts with nearly vertical moist isentropic surfaces coincident with a monsoonal surge of moisture depicted by an increase of mixing ratio 

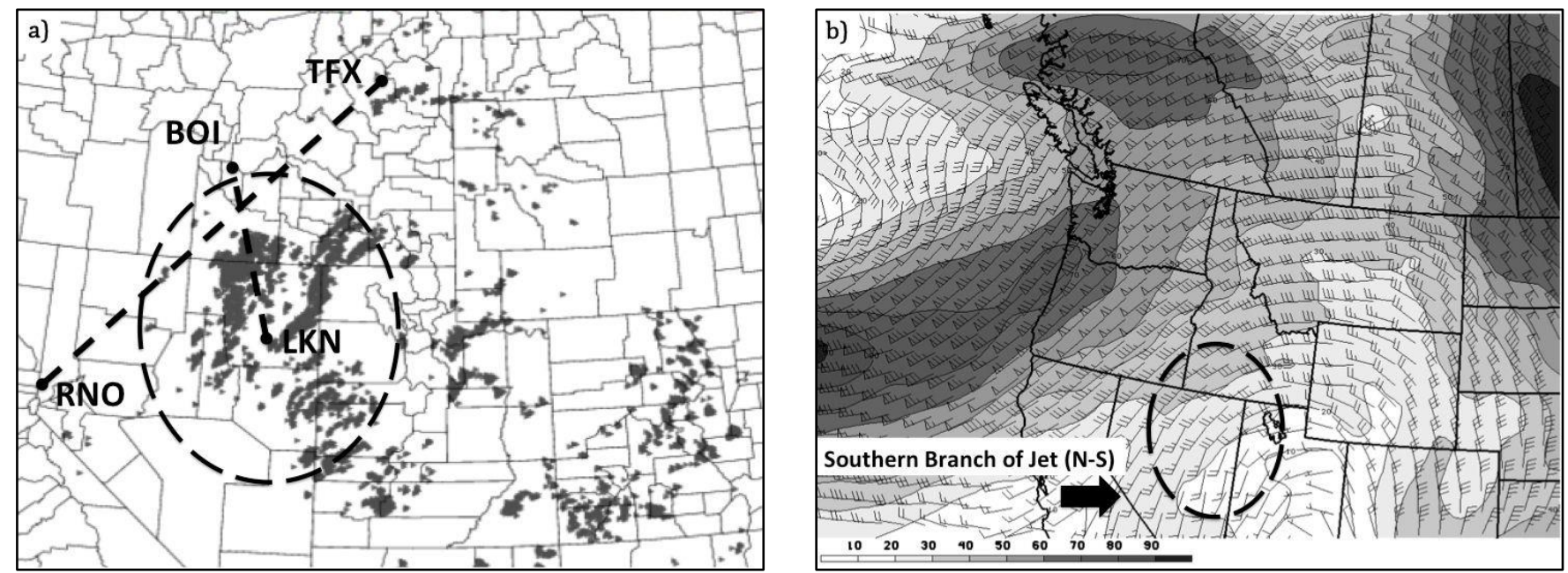

Figure 5. a) Lightning strike plot from 1200 UTC 16 July to 0000 UTC 17 July 2007; b) 1200 UTC 14 July 2007 48-h NAM forecast 250 $\mathrm{hPa}$ winds (barbs and filled every $10 \mathrm{kt}$ ). The dashed lines in a) show the location of the RNO-TFX (Reno, NV-Great Falls, MT) and LKN-BOI cross sections, and the dashed oval surrounds the area of study. N-S in b) stands for North-South.

a)



c)

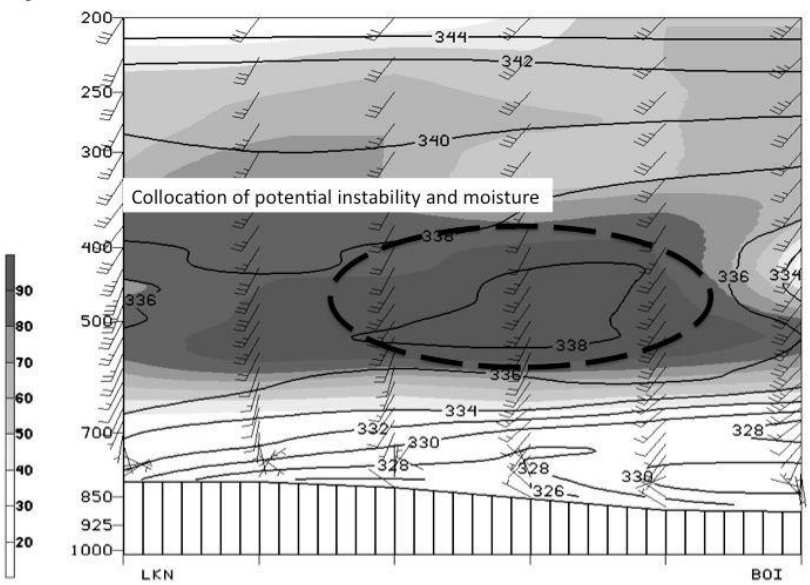

b)

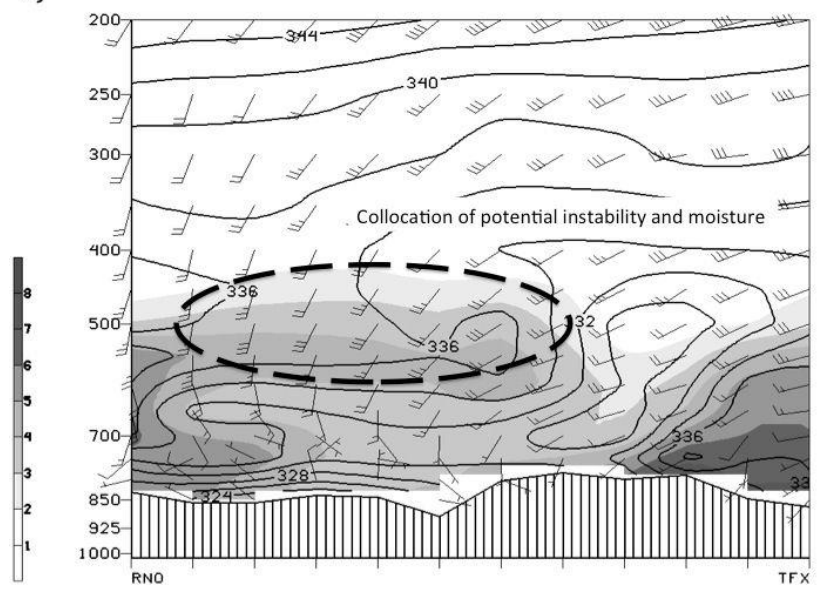

d)

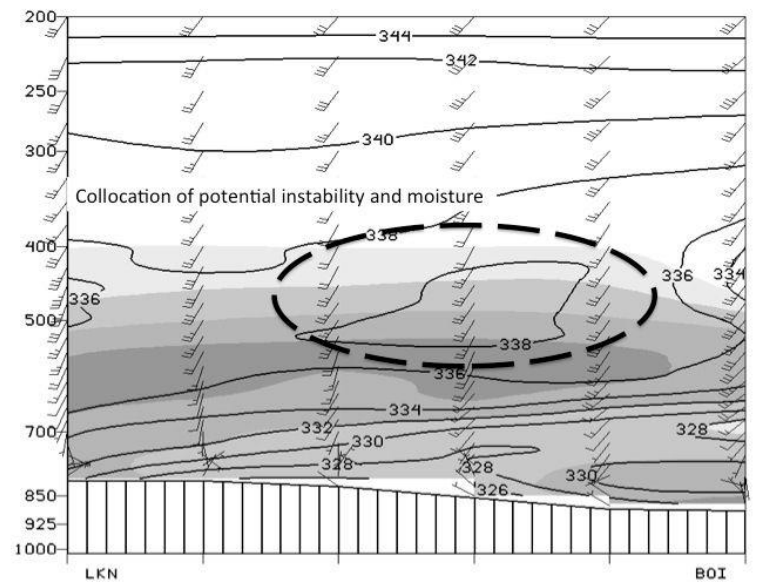

Figure 6. a) 1200 UTC 14 July 2007 48-h GFS forecast vertical cross section of RH (filled every $10 \%$ starting at 50\%) and $\theta_{e}$ (contoured every $2 \mathrm{~K}$ ) from RNO to TFX; b) 1200 UTC 14 July 2007 48-h GFS forecast vertical cross section of mixing ratio (filled every $1 \mathrm{~g} \mathrm{~kg}^{-1}$ ) and $\theta_{e}$ (contoured every $2 \mathrm{~K}$ ) from RNO to TFX; c) Same as a) except for the NAM from LKN to BOI; d) Same as b) except for the NAM from LKN to BOI. The dashed oval surrounds the collocation of PI and moisture. 
and RH across northeastern Nevada and southern Idaho. Figures $6 \mathrm{c}$ and $6 \mathrm{~d}$ display the best collocation of moisture and PI with drier lower levels from Elko, Nevada (LKN), to Boise, Idaho (BOI). The PI resulted, in part, from cooling accompanying the shortwave trough moving through the intermountain region and the moisture stream advecting from the southsouthwest to the north-northeast (i.e., from central Nevada to western Idaho). South of the area of concern-across extreme southern Nevada, southern Utah, northern Arizona, and New Mexico-monsoonal moisture penetrated the lower levels producing wetter thunderstorms, while deeper Pacific moisture existed over Montana to the north. This left northeastern Nevada and southern Idaho on the fringe of both moisture plumes, creating an environment where just enough moisture could help trigger thunderstorms, but minimize or even completely exclude surface wetting rains. Without the model forecast cross sections, the arrangement of moisture and PI would not be as apparent.

An unambiguously coherent upper-level jet streak did not exist in the area, but a mesoscale jetlet was forecast to form in northeastern Nevada (Fig. 7). While this jetlet was small in scale and did not last the entire event, it did affect the local environment. Curved jet-streak ageostrophic circulations suggest upper-tropospheric convergence would be present in northeastern Nevada, northwestern Utah, and southern Idaho as this area was near the crest of the heights at $250 \mathrm{hPa}$ (Fig. 5b; Moore and VanKnowe 1992). Additionally, if the south-to-north branch of the jet acted as a straight jet, the area of concern would reside in the right exit region, thus indicating upper-level convergence (Uccellini and Johnson 1979). However, the presence of the jetlet created upper-level divergence and subsequent ascent, and overrode the ageostrophic circulations from the larger synoptic jet during its existence of 6-12 h (Kaplan et al. 1998). The cross sections illustrate an increase of RH, with stretching of moist isentropes possibly indicating upward motion and divergence aloft across northeastern Nevada, confirming the influence of the jetlet (Fig. 6).

The remaining overlapping components of the DTP and DLP (Fig. 8) exhibit the potential for dry thunderstorms. However, the extent and magnitude of thunderstorms are less obvious with the overlapping DTP and DLP components when compared with the cross sections and 250-hPa wind and divergence plots. With most of the instability and moisture in the 700-
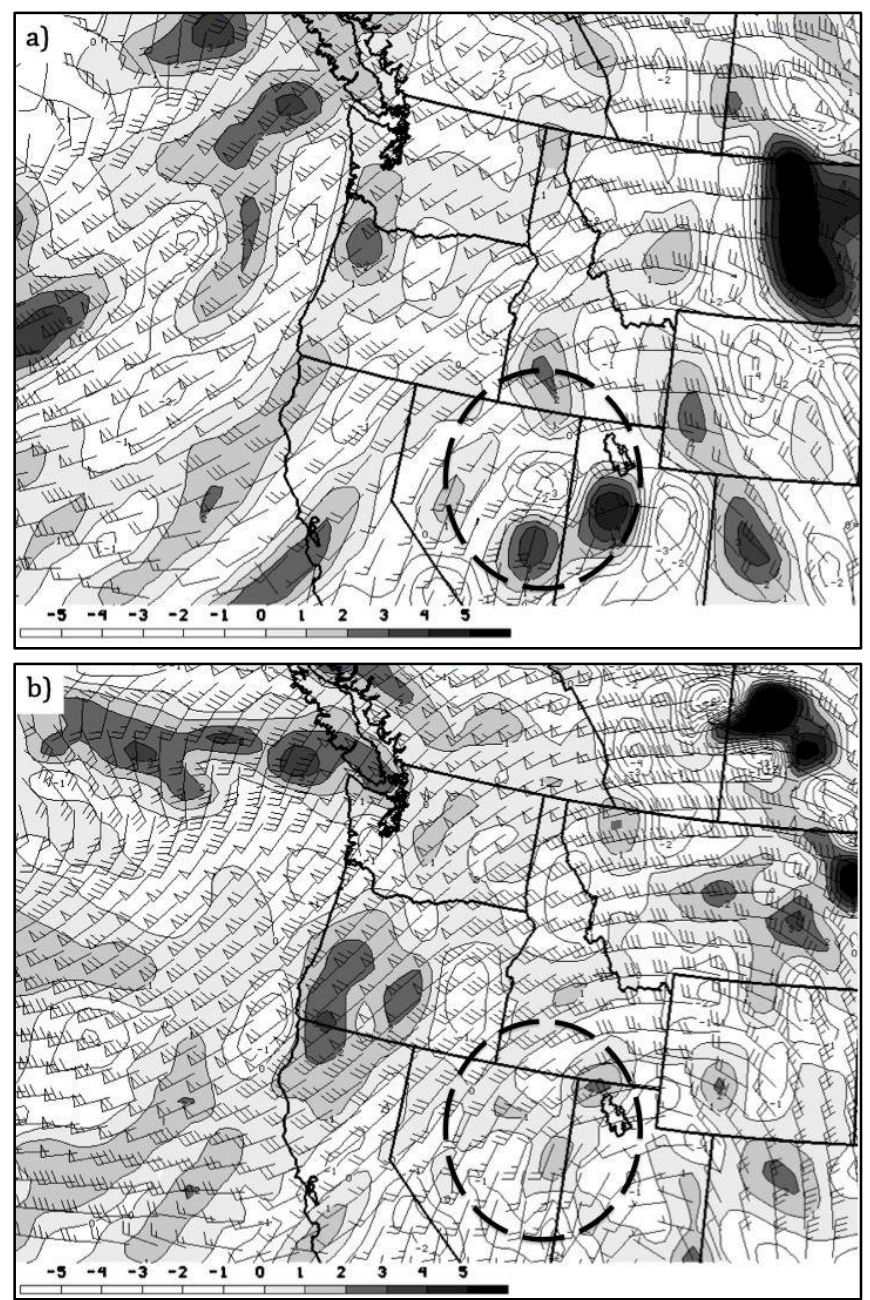

Figure 7. a) 1200 UTC 14 July 2007 48-h GFS forecast of 250$\mathrm{hPa}$ winds $(\mathrm{kt})$ and divergence (shaded, contoured every $1 \times 10^{-5}$ $\mathrm{s}^{-1}$ ); b) Same as a) except for the NAM. The dashed oval surrounds the area of the jetlet.

500-hPa layer, significantly elevated values of HLTT were expected. However, only the GFS 48-h forecast initialized at 1200 UTC 14 July 2007 indicated enhanced HLTT, including a swath of $32^{\circ} \mathrm{C}$ near the location and time of dry thunderstorm formation across eastern Nevada (Fig. 8a). A short-wave trough swept through the western Great Basin early on 16 July 2007. This feature can be seen as a pressure perturbation on the DT as well as a wind-shear zone (Figs. 8b and 8c). The NAM and GFS depicted the short-wave trough in slightly different places, but the magnitude and timing of the wave coincided closely in each simulation. The GFS UTLR 48-h forecast valid at 1200 UTC 16 July 2007 shows a swath of $7.5^{\circ} \mathrm{C} \mathrm{km}^{-1}$ values through the approximate area of dry thunderstorms in the afternoon of 16 July 2007 (Fig. $8 \mathrm{~d})$. The NAM forecast never truly showed the $7.5^{\circ} \mathrm{C}$ 

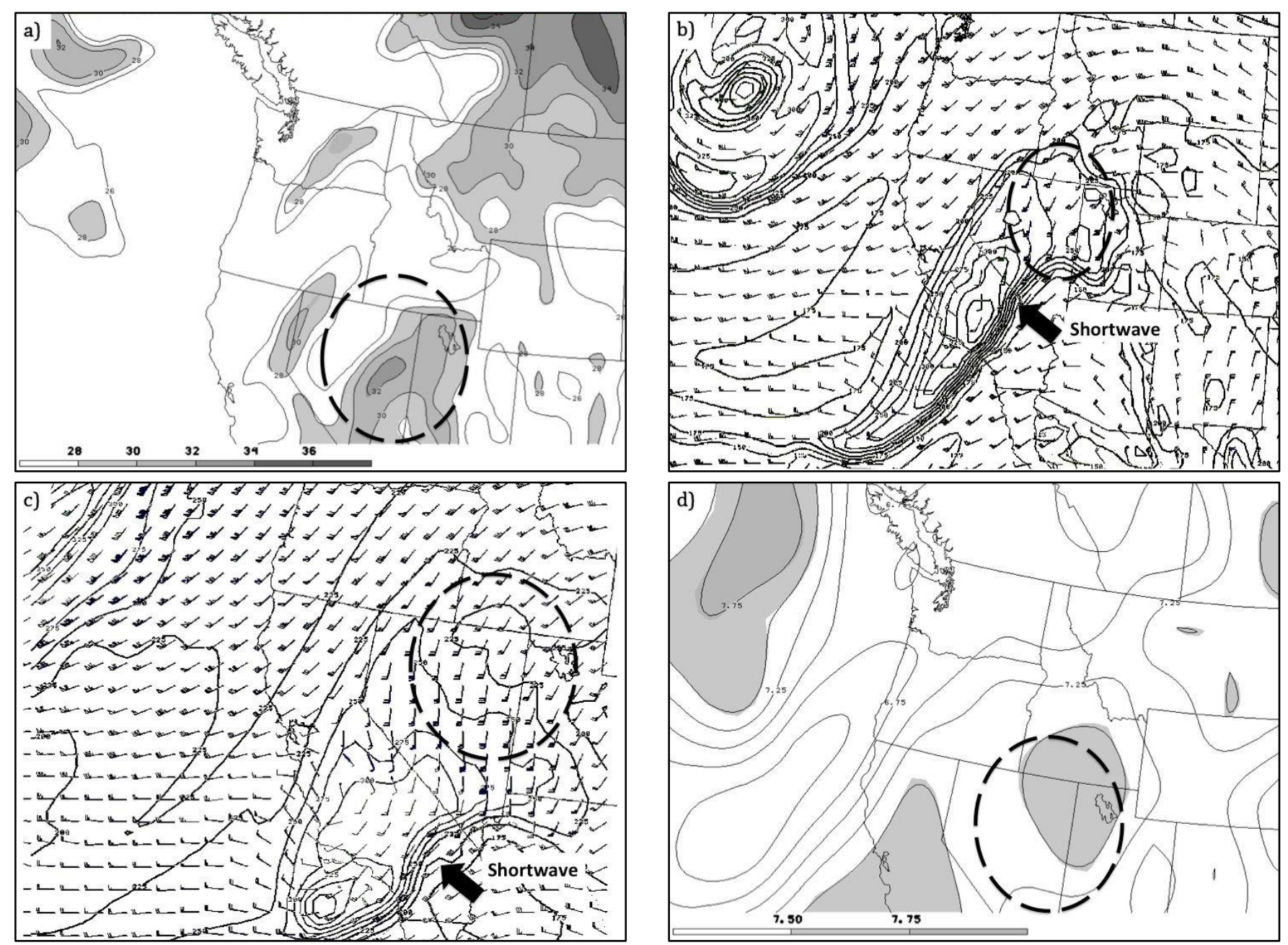

Figure 8. a) 1200 UTC 14 July 2007 48-h GFS forecast of HLTT (contoured and filled every $2^{\circ} \mathrm{C}$ ); b) 15 July 2007 36-h GFS forecast of DT pressure (contoured and filled every $25 \mathrm{hPa}$ ) and winds (kt) plotted on the $1.5 \mathrm{IPVU}$ surface; c) Same as b) except for the NAM; d) 0600 UTC 14 July 2007 42-h GFS forecast of UTLR (contoured and filled every $0.25^{\circ} \mathrm{C} \mathrm{km}^{-1}$ ). The dashed oval surrounds the study area.

$\mathrm{km}^{-1}$ threshold explicitly over the area of dry thunderstorms. It propagated from the south and west later in the event. The reasoning for lower UTLR values could be due to the bulk of the instability lying below $400 \mathrm{hPa}$ and predominantly around $500 \mathrm{hPa}$ as noted in the cross sections (Fig. 6).

The immense dry thunderstorm event that affected northern Nevada and southern Idaho lasted more than $36 \mathrm{~h}$, produced thousands of lightning strikes, and ignited hundreds of fires including more than 20 large fires (NICC 2007). The DTP demonstrated its advantage over the DLP by illustrating the collocation of the moisture and PI in the mid-troposphere via the cross sections. Additionally, a $250-\mathrm{hPa}$ straight or curved large-scale jet-streak analysis would have yielded an area not conducive for upward motion. However, the divergence plots and the discovery of the short-lived but highly divergent mesoscale jetlet provided a better picture of the structure of the troposphere over the central and northern Great Basin. Without examining the $250-\mathrm{hPa}$ wind and divergence fields and the cross sections, crucial processes to dry thunderstorm formation would be missed, and thus negatively affect the forecast of dry thunderstorms across the central and northern Great Basin.

\section{c. Overforecast: $27-28$ June 2008}

To test the reliability of the DTP, an overforecast case was examined. On the days preceding 27-28 June 2008, the NWS Monterey WFO expressed concerns about a developing weather situation. On the heels of the 20-21 June 2008 lightning event described above, the Monterey WFO examined the approaching shortwave trough and indicated that high-based, dry thunderstorms could develop over northern California 

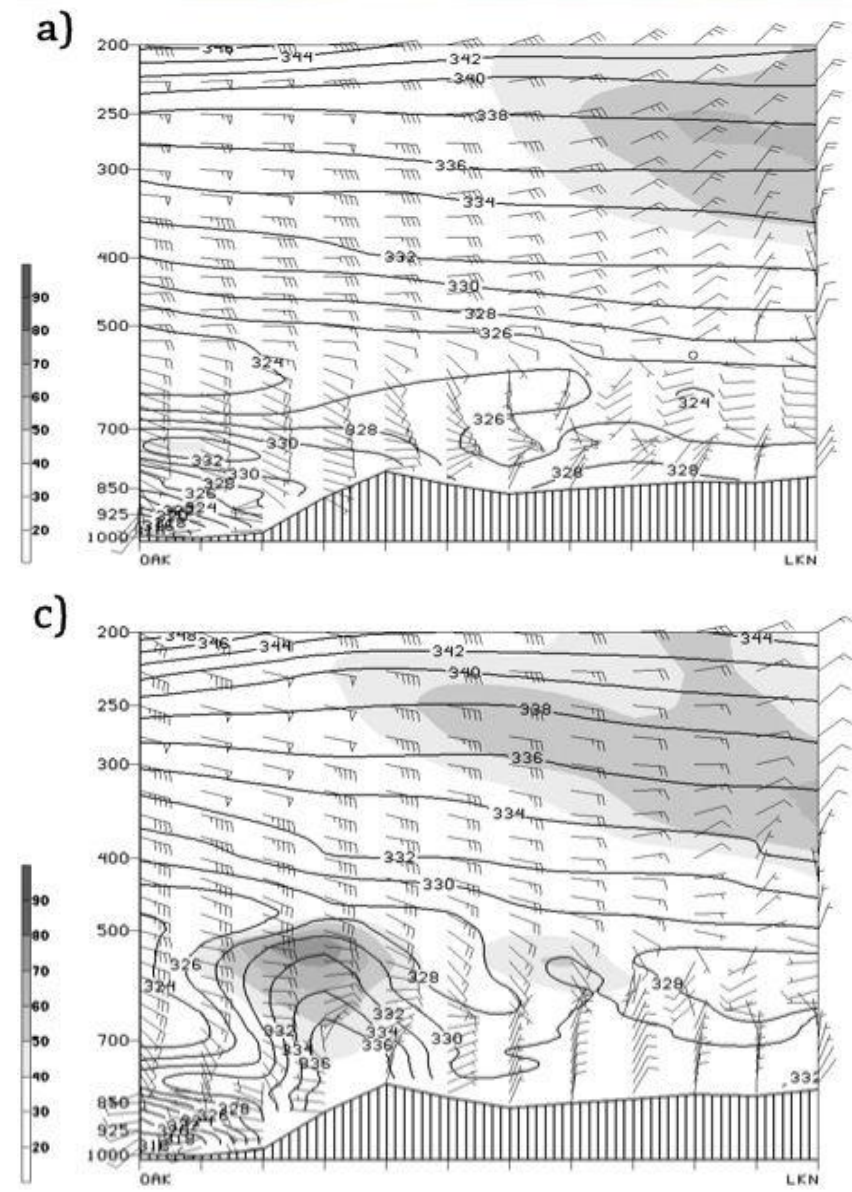



d)

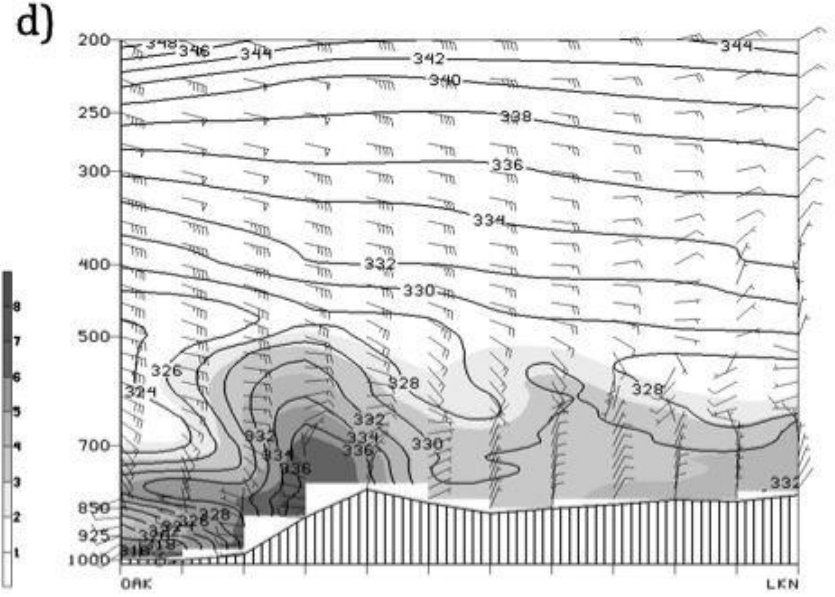

Figure 9. a) 0600 UTC 26 June 2008 36-h NAM forecast vertical cross section of RH (filled every $10 \%$ starting at $50 \%$ ) and $\theta_{e}$ (contoured every $2 \mathrm{~K}$ ) from OAK to LKN; b) 0600 UTC 26 June 2008 36-h NAM forecast vertical cross section of mixing ratio (filled every $1 \mathrm{~g} \mathrm{~kg}{ }^{-1}$ ) and $\theta_{e}$ (contoured every $2 \mathrm{~K}$ ) from OAK to LKN; c) Same as a) except for a 42-h NAM forecast; d) Same as b) except for a 42-h NAM forecast.

(Wallmann et al. 2010). The Monterey WFO issued a Fire Weather Watch. However, even with dry instability present, the moisture never became substantial enough to foster dry thunderstorm formation.

The NAM forecast cross sections (Figs. 9a and 9b) show PI over California west of the Sierra Nevada mountain range (Sierra), but very little moisture above the PBL. The GFS cross sections (not shown) revealed less moisture and did not indicate as much instability throughout the forecasting of the event. A collocation of instability, increased $\mathrm{RH}$, and mixing ratio did exist below $700 \mathrm{hPa}$ and to the east and northeast of the San Francisco Bay Area. This appears to be a feature indicative of a low-level frontal boundary, such as a sea breeze front or the mountain-plains solenoid (Tripoli et al. 1989) for the Pacific Coast Range. The smaller feature seems to have connected with the larger mountain-plains solenoid circulation of the Sierra (Figs. 9c and 9d). The increase of moisture and
PI on the upslope of the Sierra represents a common occurrence during the summer months. Temperatures exceeded $35^{\circ} \mathrm{C}$ and approached $40^{\circ} \mathrm{C}$ across the northern Central Valley in California, which would induce vigorous upslope flow during the afternoon hours. The upslope flow induced shallow cumulus clouds, but the convergence aloft, warm air aloft, and subsidence in the levels above the surface resulted in sinking motions that capped the convection, and therefore did not allow thunderstorms to develop because of too much convective inhibition. The forecasts indicated there was not enough moisture to sustain the development of thunderstorms, especially with the convergence and subsidence aloft that was heating the mid-troposphere.

Weak divergence and convergence prevailed aloft across north-central California and along the crest of the Sierra (dashed oval in Fig. 10a). Both the GFS and NAM forecasts indicated approximately the same 



Figure 10. a) 0600 UTC 26 June 2008 42-h GFS forecast of 250-hPa winds (kt) and divergence (shaded, contoured every $1 \times 10^{-5} \mathrm{~s}^{-1}$ ); b) 0600 UTC 26 June 2008 42-h NAM forecast of UTLR (contoured and filled every $0.25^{\circ} \mathrm{C} \mathrm{km}^{-1}$ ); c) 1200 UTC 26 June 200836 -h GFS forecast of DT pressure (contoured and filled every $25 \mathrm{hPa}$ ) plotted on the $1.5 \mathrm{IPVU}$ surface; d) 0600 UTC 26 June 200842 -h GFS forecast of HLTT (contoured and filled every $2^{\circ} \mathrm{C}$ ). The dashed oval surrounds the study area.

location and magnitude of convergence and weak divergence aloft. An increase of RH and stretching of moist isentropes existed across Nevada, possibly indicating divergence and lifting across northern and north-central Nevada (Fig. 9). The increase in RH and stretching of moist isentropes aloft did not appear across the California side of the Sierra-showing the lack of upper-level support for ascending motions, especially when examining the supporting uppertropospheric plots (Fig. 10). With convergence aloft stabilizing the environment, the cumulus clouds could not continue to develop vertically or increase in coverage as the environmental subsidence and subsequent adiabatic warming inhibited them. The UTLR did not meet dry thunderstorm criteria, further demonstrating the lack of upper-level support for destabilization (Fig. 10b). Sufficient UTLR values existed over far northern California and parts of northern Nevada, but a lack of moisture and mid- to upper-level instability hampered convective development in those areas.

A short-wave trough approached this region as diagnosed from the DT on the 1.5 IPVU surface (Fig. 10c). Both the NAM and GFS forecasts showed the sequence of undulations from a very short and weak precursor trough, followed by a rise in the DT, and then followed by a more dynamic short-wave trough moving into the region from south to north. The main dynamics lagged behind and did not coincide well enough with upper-level lifting and moisture from the Pacific or via the monsoonal moisture at upper levels. The GFS HLTT forecast showed a pocket of substantial values over the crest of the Sierra in and around Lake Tahoe (Fig. 10d). This demonstrates a 
shortcoming of the HLTT. When some moisture is present along with strong upslope flow, the moisture and instability can penetrate into the layer that the HLTT represents, thus raising HLTT values to deceptively large magnitudes.

The inspection of the cross sections and $250-\mathrm{hPa}$ divergence plots was crucial to the event. If a forecaster applied the DLP, a forecast of dry thunderstorms could have been inaccurately produced. It also could be argued that looking at the DTP, a chance of dry thunderstorms still would be forecasted, although not as definitively as the DLP implied. This case also demonstrates the sensitivity of dry thunderstorm formation to not only the amount of moisture and instability, but also the location of moisture and PI horizontally and vertically across a region.

\section{Summary, conclusions, and future work}

For both of the lightning events, the DTP correctly depicted the magnitude and location of dry thunderstorm formation, whereas the overforecast case suggests that the application of the DTP can work in diverse scenarios to prevent false alarms. Some discrepancies between the models were revealed, but by using both the GFS and NAM operational models, the loss of congruency while implementing the DTP was somewhat minimized. In the cases examined, most of the DTP criteria were met, and if one part of the procedure was weak in magnitude, others usually demonstrated more robust values to compensate. The DTP shows that not only the existence, but also the strength of each component could lead to better forecasting of dry thunderstorm events as well as how strong and widespread the events will be.

The flexibility of the DTP is its strongest asset. The encompassing components of the DTP form a group of ingredients for dry thunderstorm formation. The cross section plots with $\theta_{e}$ and mixing ratio or $\mathrm{RH}$ illustrate moisture and instability in more detail than constant-pressure plots. Straight and curved jet-streak analyses per Uccellini and Johnson (1979) and Moore and VanKnowe (1992) diagnosed from 250-hPa wind and divergence fields provided insight to upper-level support for thunderstorm formation. The UTLR provides a numerical value of instability just below $250 \mathrm{hPa}(500-300-\mathrm{hPa}$ layer) and couples the mid- to the upper-troposphere. The HLTT shows the 700-500$\mathrm{hPa}$ layer where much of the instability and moisture exist in dry lightning events. Finally, the pressure of the DT on the 1.5 IPVU surface depicts undulations of the tropopause and highlights short-wave troughs that constant-pressure maps underestimate or miss entirely. Each DTP component measures instability or moisture - and in some instances both instability and moisture - that are key to thunderstorm formation. The components of the DTP bring these features to the forefront and allow forecasters to determine if thunderstorms will form, and if they will be dry or wet in a qualitative manner. It also allows for forecasters to impart local knowledge to enhance the DTP by allowing the locations of the cross sections to be determined by the forecasters.

Comparing the DTP and DLP directly for the 2021 June 2008 and 16-17 July 2007 dry thunderstorm cases demonstrates the advantages of the additions of cross sections and divergence to the $250-\mathrm{hPa}$ winds by explicitly and efficiently illustrating the collocation of moisture and PI in the mid-troposphere to a highly divergent and rapidly evolving jetlet aloft. The DTP demonstrates its effectiveness by correctly resolving pockets of PI and moisture in addition to finer scale jet-streak features such as jetlets. This comparison gives confidence that a detailed future comparison of techniques needs to be performed to unambiguously test these additions to the DLP.

A common theme for each event emerged, which is the collocation of PI and moisture as a secondary region on the periphery of the most favorable PI and moisture for wet thunderstorm development within the 700-400-hPa layer (Figs. 11 and 12). This secondary region typically accompanies a negatively tilted upperlevel trough with monsoonal surges and approaching Pacific systems interacting in complex ways over the western United States. Moisture and PI may come from multiple source regions at very fine scales of motion, thus making forecasting these dry thunderstorm events more challenging.

The DTP conceptual summary includes the following elements (Figs. 11 and 12):

- an approaching short-wave trough to help provide instability (trend of negatively tilted troughs emerging);

- monsoonal and/or Pacific moisture in front of and/or entrained with approaching trough in the mid-troposphere;

- collocation of instability and moisture within the 700-400-hPa layer, with drier lower troposphere underneath the pairing; and 


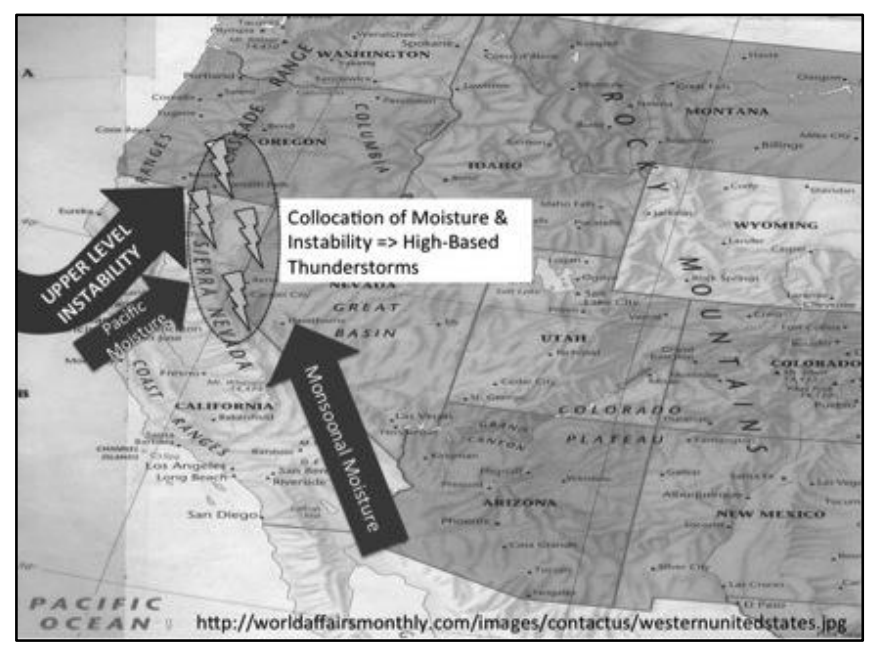

Figure 11. Planar schematic of dry thunderstorm ingredients identifying the collocation of different moisture sources with instability aloft. Map background from worldaffairsmonthly.com/ images/contactus/westernunitedstates.jpg.



Figure 12. Dry thunderstorm schematic showing an elevated moisture source (monsoonal and/or Pacific) coinciding with dynamical destabilization in the mid-troposphere to produce PI and high-based convection. For dry thunderstorms, the collocation of the moisture and instability usually resides on the fringes of the deepest moisture and strongest dynamical destabilization.

- the ideal environment resides on the periphery of most favorable moisture and instability for wet thunderstorms where the magnitude and location of each allow for thunderstorm development, but not widespread wetting thunderstorms.

It is recognized that more research on dry thunderstorm cases and overforecast events would further validate the DTP. With a larger sample size, forecast statistics would measure the effectiveness not only qualitatively, but also quantitatively. More objec- tive analyses also could include moisture and instability thresholds in the low- to mid-troposphere to determine the wet or dry nature of the environment. Owing to the temporal and spatial sensitivity of PI and moisture, the DTP would not be a strong candidate to apply to a forecast beyond $48 \mathrm{~h}$ because of the anticipated diminishing forecast skill.

Acknowledgments. The authors thank UCAR, the NWS, and the Cooperative Program for Operational Meteorology, Education, and Training $\left(\mathrm{COMET}^{\circledR}\right)$ for funding this project ("Development of the WN09 Dry Thunderstorm Forecast Procedure"). The authors also thank Dr. John Lewis, Dr. Fred Harris, and Dr. Sim Larkin for their input and guidance throughout the project. Hauss Reinbold and Dr. Kevin Goebbert helped immensely with the seemingly infinite computer programming issues. Additionally, many thanks to the atmospheric graduate students at the University of Nevada, Reno-especially KC King, Ben Hatchett, and Andrew Joros. Finally, the authors thank Don Scronek and Tim Mathewson who provided opportunities to implement the DTP and learn about firefighting and fire management.

\section{REFERENCES}

Bothwell, P. D., 2002: Prediction of cloud-to-ground lightning in the western United States. Ph.D. dissertation, University of Oklahoma, $178 \mathrm{pp}$.

, 2005: Development of an operational statistical scheme to predict the location and intensity of lightning. Preprints, Conf. on the Meteorological Applications of Lightning Data, San Diego, CA, Amer. Meteor. Soc., 4.2. [Available online at ams.confex.com/ ams/Annual2005/webprogram/Paper85013.html.]

, 2009: Development, operational use, and evaluation of the perfect prog national lightning prediction system at the Storm Prediction Center. Preprints, Fourth Conf. on the Meteorological Applications of Lightning Data, Phoenix, AZ, Amer. Meteor. Soc., 6.2. [Available online at ams.confex.com/ams/89annual/webprogram/ Paper150697.html.]

David, C. L., 1976: A study of upper air parameters at the time of tornadoes. Mon. Wea. Rev., 104, 546-551.

Doswell, C. A., III, Ed., 2001: Severe Convective Storms. Meteor. Monogr., No. 50, Amer. Meteor. Soc., 561 pp.

Douglas, M. W., R. A. Maddox, K. Howard, and S. Reyes, 1993: The Mexican monsoon. J. Climate, 6, 16651677.

Hamilton, D. W., Y.-L. Lin, R. P. Weglarz, and M. L. Kaplan, 1998: Jetlet formation from diabatic forcing with applications to the 1994 Palm Sunday tornado outbreak. Mon. Wea. Rev., 126, 2061-2089.

Hirschberg, P. A., and J. M. Fritsch, 1991a: Tropopause undulations and the development of extratropical 
cyclones. Part I: Overview and observations from a cyclone event. Mon. Wea. Rev., 119, 496-517.

, and _ , 1991b: Tropopause undulations and the development of extratropical cyclones. Part II: Diagnostic analysis and conceptual model. Mon. Wea. Rev., 119, 518-550.

Kaplan, M. L., Y.-L. Lin, D. W. Hamilton, and R. A. Rozumalski, 1998: The numerical simulation of an unbalanced jetlet and its role in the Palm Sunday 1994 tornado outbreak in Alabama and Georgia. Mon. Wea. Rev., 126, 2133-2165.

Mesinger, F., and Coauthors, 2006: North American Regional Reanalysis. Bull. Amer. Meteor. Soc., 87, 343-360.

Milne, R., 2004: A modified total totals index for thunderstorm potential over the Intermountain West. NOAA/NWS WR Tech. Attach. 04-04, 15 pp. [Available online at www.wrh.noaa.gov/media/wrh/ online publications/TAs/ta0404.pdf.]

Moore, J. T., and G. E. VanKnowe, 1992: The effect of jetstreak curvature on kinematic fields. Mon. Wea. Rev., 120, 2429-2441.

NICC, cited 2006: Incident management situation report: Tuesday, June 27, 2006 - 0530 MDT. National Interagency Coordination Center, National Interagency Fire Center, Boise, ID, 14 pp. [Available online at www.predictiveservices.nifc.gov/IMSR/2006/20060627 IMSR.pdf.]

, cited 2007: Incident management situation report: Tuesday, July 17, 2007 - 0530 MDT. National Interagency Coordination Center, National Interagency Fire Center, Boise, ID, 15 pp. [Available online at www.predictiveservices.nifc.gov/IMSR/2007/20070717 IMSR.pdf.]

, cited 2009: Incident management situation report: Tuesday, August 2, 2009 - 0530 MDT. National Interagency Coordination Center, National Interagency Fire Center, Boise, ID, 11 pp. [Available online at Www.predictiveservices.nifc.gov/IMSR/2009/20090802 IMSR.pdf.]

NWS, cited 2007: Advanced Weather Interactive Processing System (AWIPS). NOAA/National Weather Service, [Available online at www.nws.noaa.gov/ops2/ops24/ awips.htm.]
Nauslar, N. J., 2010: A forecast procedure for dry thunderstorms. M.S. thesis, Department of Physics/ Division of Atmospheric Sciences (Desert Research Institute), University of Nevada, Reno, 108 pp. [Available online at www.cefa.dri.edu/Publications/ Thesis_Complete_Final.pdf.]

Orlanski, I., 1975: A rational subdivision of scales for atmospheric processes. Bull. Amer. Meteor. Soc., 56, 527-530.

Rorig, M. L., and S. A. Ferguson, 1999: Characteristics of lightning and wildland fire ignition in the Pacific Northwest. J. Appl. Meteor., 38, 1565-1575. , and __, 2002: The 2000 fire season: Lightningcaused fires. J. Appl. Meteor., 41, 786-791. , S. J. McKay, S. A. Ferguson, and P. Werth, 2007: Model-generated predictions of dry thunderstorm potential. J. Appl. Meteor. Climatol., 46, 605-614.

Stull, R. B., 2000: Meteorology for Scientists and Engineers. 2nd ed. Cengage Learning, 528 pp.

Tripoli, G. J., and W. R. Cotton, 1989: Numerical study of an observed orogenic mesoscale convective system. Part 2: Analysis of governing dynamics. Mon. Wea. Rev., 117, 305-328.

Uccellini, L. W., and D. R. Johnson, 1979: The coupling of upper and lower tropospheric jet streaks and implications for the development of severe convective storms. Mon. Wea. Rev., 107, 682-703.

UCAR, 2002: Isentropic Analysis. University Corporation for Atmospheric Research, Cooperative Program for Operational Meteorology, Education, and Training (COMET). [Available online at www.meted.ucar.edu/ isen_ana.]

Wallmann, J., 2004: A procedure for forecasting dry thunderstorms in the Great Basin using the dynamic tropopause and alternate tools for assessing instability. NOAA/NWS WR Tech. Attach. 04-08, 20 pp. [Available online at www.wrh.noaa.gov/media/wrh/ online_publications/TAs/ta0408.pdf.]

, R. Milne, C. Smallcomb, and M. Mehle, 2010: Using the 21 June 2008 California lightning outbreak to improve dry lightning forecast procedures. Wea. Forecasting, 25, 1447-1462. 